\title{
EFFECTS OF COGNITIVE APPRAISAL PATTERN ON PROBABILITY WEIGHING FUNCTION AND RISK BEHAVIOR BETWEEN GENDERS
}

\author{
Kean-Siang Ch'ng* \\ Universiti Sains Malaysia
}

\begin{abstract}
The paper sets out to explore the effect of manipulating the appraisal dimensions, controllability and certainty, which was induced by emotions fear and anger, on probability weighting of a risky prospect between genders. By targeting the risk perception dimensions; subjects' perception on the controllability and certainty of a situation were investigated. The experimental subjects were then asked to make choices in a lottery game. The results showed that high controllability and certainty dimensions could mitigate over-reaction to probability of losing among women. However, we found no effect of the two dimensions on men. Past studies have shown women were emotionally more sensitive and tend to overweigh probability of losing higher than men. This misperception of probability has large consequences on income discrepancy, risk tolerance and investment decisions between genders. This paper showed manipulating the controllability and certainty dimensions when faced with a risky choice could mitigate the misperception of risk.
\end{abstract}

Keywords: Risks; Appraisal Dimensions; Probability weighing; Lottery; Experiment.

\section{INTRODUCTION}

Gender differences in propensity to take risk has been widely studied and documented in the literature (Byrnes, Miller, \& Schafer, 1999; Eckel \& Grossman, 2008; Rachel \& Gneezy, 2009). The majority of the results pointed to the finding that females were less willing to take risk than males in both abstract experimental and contextual studies. Recent works have begun to study the cognitive underpinnings of the differences in risk perception and evaluation behaviors. Weber, Blais, and Betz (2002) found that males displayed higher likelihood to engage in risky activities than females, Holtgrave and Weber (1993) and Slovic, Fischhoff, and Lichtenstein (2000) proposed that psychological risk dimensions such as dread, lack of knowledge and control over a situation contributed to risk perception. This caused females to assign higher probability on a risky prospect than males (Eriksson \& Simpson, 2010; Fehr-Duda, De Gennaro, \& Schubert, 2006). If psychological risk dimensions could influence the evaluation of probability, one may mitigate or reverse the misperception of probability by influencing the perceptions to the said risk dimensions when faced with a risky prospect. The present paper attempts to explore this possibility.

*Corresponding author: Economics Department, School of Social Sciences, Universiti Sains Malaysia; Email: cks@usm.my; Phone: +6046534623, Fax: +6046530718 
The tendency to overweigh probability of losing and shun risky prospects has been shown to have far reaching consequences to the women's future financial well being, choice of occupations and income distribution gap between genders. In the study by Niederle and Vesterlund (2007), women were found to prefer non-competitive compensation scheme compared to men who preferred more competitive environment such as tournament competition. This was because men tend to be more optimistic about the likely consequences of a risky situation compared to women. Women were also found to be less likely to compete and secure a lucrative job. The low representation of women in the highest paid executive positions in the corporate world is the main concern of income distribution gap between genders (Bertrand \& Hallock, 2001). In financial decision, women were found to be more conservative and risk averse than men. In a series of study on the effect of genders differences in risk aversion on investment decision, John Watson and Mc Naughton (2007), Sunden and Surette (1998), Olsen and Cox (2001) and Watson and Robinson (2003) found that lower risk tolerance among women affected the choice of investment decision and returns.

In a recent literature on gender differences on risk, Rachel and Gneezy (2009) highlighted the emotional factors may drive women to experience stronger reactions to winning or losing, and the reason behind differences in risk tolerance between genders. Women were more sensitive to emotion and experience more intense nervousness than men This instinctive and intuitive reaction to risk caused women to be more likely to experience fear in losing relative to men (Lerner, Gonzalez, Deborah \& Baruch, 2003). In an empirical test on the effect of emotion on probability evaluation, Bingley and Eriksson (2001) found that women expressed stronger emotional reactions to winning and losing a lottery than men. The negative feeling of fear of losing discouraged women to enter a lottery game, but positive feeling of gaining did not have any effect on decision. FehrDuda et al. (2006) found that women tend to overreact to small probability, which caused them to be more risk seeking in winning lottery and risk averse in losing lottery. Women were also found to be more sensitive to probability, while men were more concern about outcome (Harris, Jenkins, \& Glaser, 2006; Levy \& Baron, 2005).

Sensitivity to emotion can be exploited by providing information that can influence appraisal pattern relevant to a risky situation. For example, situation that induces emotion fear is appraised as highly uncontrollable and uncertain, which causes risk aversion (Lerner \& Keltner, 2000) (The appraisal patterns will be explained in the next section). Therefore, targeting and manipulating these two dimensions could influence how people perceive and make decision. Past literature has shown many instances where judgment errors are mitigated by providing more salient information to reduce misperception of probability (Camerer \& Howard, 1989; DeVaney, Gorham, Bechman, \& Haldeman, 1995; Felton, Gibson, \& Sanbonmatsu, 2003). The present paper investigates how psychological dimensions such as "controllability" and "certainty" could improve decision- making.

We conducted laboratory experiments to study the effects of the two dimensions, controllability and certainty, on probability weighing function (Kahneman \& Tversky, 1979) of both genders in a lottery game. We induced the two said dimensions through emotions fear and anger. Fear is associated with low in controllability and certainty, and emotion anger is evaluated highly in controllability and certainty dimensions (see, for example, Lerner and Keltner (2000); Smith and Ellsworth (1985)). The dimensions "low 
controllability" and "low certainty" induced should reduce the tendency to overweigh or place too high decision weight on small probability of winning a lottery and underweigh high probability of losing. High controllability and certainty should help to avoid placing too high decision weight on small probability of losing and underweigh high probability of winning. We examine the effects by comparing the controlled groups with main groups.

From the results, women were found to be too optimistic in gain domain; although the actual probability of winning is small, they perceived higher chances to win. In the loss domain with small probability, they perceived higher chances to lose. The results from the controlled groups conform to the findings in literature (Eriksson \& Simpson, 2010; Fehr-Duda et al., 2006). The misperception of probability was mitigated in the main groups. High controllability and certainty induced through emotion anger caused subjects to be more optimistic, they placed lower decision weight on small probability of losing than controlled groups. And in the gain domain, women placed lower decision weight on probability of winning. We did not find any significant effect of both dimensions on the decision weight when the probability is large and the two dimensions did not influence men.

\section{BRIEF REVIEW OF APPRAISAL TENDENCY FRAMEWORK (ATF)}

Research in judgment and decision-making has begun to incorporate affect into what was once thought to be governed by cognitive process when faced with uncertain situation (Loewenstein, 2000; Loewenstein, Weber, Hsee \& Welch, 2011). Lerner and Keltner (2000) has proposed the Appraisal Tendency Framework to examine the appraisal patterns when under the influence of certain emotion. The framework assumes emotions are associated with specific cognitive appraisal dimension of a situation, which differentiates emotional experience and effects on perception and preferences in decision-making process. Smith and Ellsworth (1985) identified six appraisal dimensions underlying different emotions: certainty, control, pleasantness, attentional activity, responsibility and anticipated effort. Under the influence of certain emotion, specific appraisal pattern will predispose individuals to act in a specific way to adapt to a situation.

Although traditionally the patterns were conceptualized as causes of emotion (cognition to emotion), Berkowitz (1990) and Berkowitz and Harmon-Jones (2004), found that the patterns did not play a causal role in creating the emotion, but the corresponding appraisal patterns were experienced nonetheless. This implies although the emotion evoked in an event, the appraisal tendency patterns persists beyond the eliciting situation. This emotion-related processes guide subsequent behavior and cognition in directed ways, even in response to the events that are not related to the original cause of the emotion (Gasper \& Clore, 1998; Lerner \& Keltner, 2001).

The experiences of anger and fear have been widely studied. The emotion anger has been found to be associated with a sense of certainty and confidence about what has happened and what was the cause of an event (Lerner \& Tiedens, 2006) and people formed a notion that self can influence or cope with the situation (Finucane, Alhakami, Slovic, \& Johnson, 2000; Smith \& Ellsworth, 1985). Emotions anger and fear differed significantly in the 
appraisal patterns in terms of certainty and control. As mentioned, emotion anger triggers sense of ability to cope and control a situation, but fearful people will perceive an event to be situational control and therefore uncertain. In the present paper, we examine the effects of these two appraisal patterns on probability weighing function in a lottery game.

\section{EXPERIMENTAL DESIGN}

\subsection{Participants}

We conducted 2 (emotion: fear and anger) $\times 2$ (gender: male and female) main treatment designs. We recruited 40 undergraduate students for each main treatment and 20 subjects for each controlled treatment (i.e. male and female without emotion induction) through class announcements. Overall, we recruited 200 subjects (the 4 main treatments consist of: 40 subjects in male for emotion fear, 40 in male for emotion anger, 40 in female for emotion fear, 40 in female for emotion anger, and two control treatments consists of: 20 in male and 20 in female). Students were promised a payoff for spending their time in the laboratory but the purpose and nature of the experiments were not disclosed during recruitment. The participants were recruited from various faculties from a University.

Upon entering the lab, they were randomly assigned a seat and a computer. They were separated by a partition to ensure no communication during the experiment. They were briefed about the tasks they had to perform and the payoff depended on the decision they made in the experiment. They were told the experiment was divided into two stages. The first stage required them to recall and write down real experience that caused them to feel angry or fearful, and the second stage was a lottery game. The experimenter addressed any question raised during briefing before the experiment started.

\subsection{Emotion Induction}

We induced both emotions fear and anger through a writing task used by, among others, Kugler, Connolly, and Ordonez (2010), Lerner and Keltner (2000), Smith and Ellsworth (1985) and Fessler, Pillsworth, and Flamson (2004). Participants were asked to write down their own experience in detail an event that made them strongly feel the emotions. They were told it must be from own experience and not from the experience from other people, from movies or from other sources. The description should be enough detail so that a person who would be assigned to read it would feel the same emotion after reading the event. The subjects were told they would be disqualified from proceeding to the next stage of the experiment or they had to rewrite if they did not fulfill the requirement.

To ensure they understood the requirement and to allow experimenter knew how the event triggered the targeted emotions, we asked the subjects to answer 5 questions (adopted from Smith and Ellsworth (1985)):

1. Please describe the past angry (fearful) situation to me. What was it like to be angry (fearful) in this situation?;

2. What happened in this situation to make you feel angry (fearful)?;

3. Why did these things make you feel angry (fearful)?; 
4. How did you know that you were angry (fearful) in this situation?;

5. What did it feel like for you to be angry (fearful) in this situation?; and

The written experience and answers to the above question would then be read and assessed by the independent readers (research officers). Subjects who were found did not fulfill the requirement would be disqualified, paid a show-up fee and asked to leave the experiment.

The subjects would then proceed to rate their experience based on "control" and "certainty" dimensions as used in ATF. These dimensions are cognitive appraisal patterns associated with a situation when under the influence of certain emotion. When a person is angry, he will appraise the situation as highly certain and in control. He knows why or who causes him to be angry and is sure what is happening in the surrounding which triggers the anger. The dimension control refers to the perception that they have the ability to control the situation when angry. Contrary to emotion anger, fearful subjects will appraise a situation to be uncertain of what is happening around them and have less control over the situation.

Subjects in the experiment were asked to rate both dimensions based on the 11-point scale, ranging from "not at all" (1) to "extremely" (11) to the questions listed in Table 1. After they had finished answering the questions, the experiment proceeded to the next stage which involved a lottery game.

Table 1: Questions to evaluate control and certainty dimensions

\section{Items on the Dimensional Ratings Questionnaire (with angry emotion)}

\section{Control}

1. (Situational-Control) When you were feeling angry, to what extent did you feel that circumstances beyond anyone's control were controlling what was happening in this situation?

2. (Self-Control) When you were feeling angry, to what extent did you feel that you had the ability to influence what was happening in this situation?

\section{Certainty}

3. (Understand) When you were feeling angry, how well did you understand what was happening around you in this situation?

4. (Certainty) When you were feeling angry, how certain were you about what was happening in this situation?

5. (Predict) When you were feeling angry, how well could you predict what was going to happen in this situation?

\subsection{Lottery}

In this stage, subjects would have to decide on whether to choose a lottery or a guaranteed amount. A lottery was assigned 5\%,50\% and 95\% probability of winning a payoff. We assigned payoff of $\$ 20$ and $\$ 40$ for each level of probability, so overall we had 6 lotteries with $\mathrm{L} 1(0.05,20 ; 0.95,0)$ and $\mathrm{L} 2(0.05,40 ; 0.95,0)$ for small probability $0.05, \mathrm{~L} 3(0.5,20$; 
$0.5,0)$ and $\mathrm{L} 4(0.5,40 ; 0.5,0)$ for medium probability 0.5 , and $\mathrm{L} 5(0.95,20 ; 0.05,0)$ and L6 $(0.95,40: 0.05,0)$ for large probability of 0.95 . We conducted the lottery game in both gain and loss domains. In the loss domain, the positive payoffs were changed to negative amount. In total there were 12 lottery games; 6 each in gain and loss domains.

The guaranteed amount was arranged in a descending order (ascending order) in gain domain (loss domain). The first guaranteed amount was equivalent to the amount of payoff of a lottery, and decremented until it reached a minimum amount. For example, in the lottery with $\mathrm{L} 1(0.05,20 ; 0.95,0)$, the guaranteed amount started with $\$ 20$ and decremented with equal step until it reached \$2 payoff. Each lottery game consisted of 10 choices, so the guaranteed amount in lottery L1 $(0.05,20 ; 0.95,0)$ was decremented by $\$ 2$.

During the experiment, a subject had to decide to choose either option A (the lottery) or option B (the guaranteed amount). Since we had 12 lottery games (6 in gain and 6 in loss domains), each lottery game was randomly chosen and was not repeated. Subjects had to play all 12 lottery games. Table 2 below shows an example of the lottery game with the guaranteed amount. During the experiment, subjects were not allowed to switch decision more than once.

Table 2: The choice screen used during the lottery game

\begin{tabular}{cccc}
\hline \hline \multicolumn{3}{c}{ Decision 1 } \\
\hline Choice & Option A & Option B & State your option A or B \\
\hline 1 & & 20 \\
2 & & 18 & \\
3 & & 16 \\
4 & & 14 \\
5 & Probability 5\% to win \$20 & 12 \\
6 & and 95\% to win 0 & 10 \\
7 & & 8 \\
8 & & 6 \\
9 & & 2 \\
10
\end{tabular}

We derived the certainty equivalent (CE) based on the decisions made in the lottery game. The amount was the average of two guaranteed amounts at the point when subjects switched their decisions. For example, suppose a subject chose guaranteed amount from choice 1 to choice 6 in Table 2 before he switched to option A in choice 7. The amount $\mathrm{CE}$ would be calculated as $\$ 9(10+8 / 2)$. We used the amount to examine how much a lottery was worth as perceived by the subjects.

\section{RESULTS}

\subsection{Control and certainty dimensions}

Table 3 shows the mean score for each dimension according to gender. Subjects under emotion anger expressed higher self-control and lower situational control compared to 
fearful subjects. Emotion anger caused subjects to perceive a situation to be more certain and predictable than fearful subjects. Wilcoxon matched-paired tests reveal that the difference of scores between emotions for each dimension is significantly different below $1 \%$ level. We can conclude that both appraisal patterns "Controllability" and "Certainty" were successfully induced in the experiment.

Table 3: Mean scores of each dimension according to emotion

\begin{tabular}{cccccccc}
\hline \hline \multirow{2}{*}{ Gender } & \multicolumn{3}{c}{ Anger } & & \multicolumn{3}{c}{ Fear } \\
\cline { 2 - 5 } \cline { 6 - 8 } & All & Male & Female & & All & Male & Female \\
\hline Situation control & $4.71^{*}$ & $4.92^{*}$ & $4.57^{*}$ & & 7.95 & 7.72 & 8.1 \\
Self-control & $5.15^{*}$ & $5.33^{*}$ & $5.03^{*}$ & & 2.64 & 2.95 & 2.43 \\
Understand & $8.66^{*}$ & $8.47^{*}$ & $8.78^{*}$ & & 5.62 & 5.92 & 5.42 \\
Certain & $8.70^{*}$ & $8.85^{*}$ & $8.60^{*}$ & & 5.59 & 5.9 & 5.38 \\
Predict & $6.99^{*}$ & $6.95^{*}$ & $7.01^{*}$ & & 3.63 & 3.83 & 3.5 \\
\hline \hline
\end{tabular}

Note: the symbol * denotes the difference between emotion is statistically significant below 1 percent level.

\subsection{Fourfold pattern of risk}

Table 4: Fourfold pattern of risk based on CE and EP

\begin{tabular}{|c|c|c|c|c|c|c|c|c|c|}
\hline \multirow{3}{*}{ Lottery } & \multirow{2}{*}{\multicolumn{3}{|c|}{$\begin{array}{c}\text { Female } \\
\text { angry }\end{array}$}} & \multirow{2}{*}{\multicolumn{3}{|c|}{$\begin{array}{c}\text { female } \\
\text { fear } \\
\end{array}$}} & \multirow{2}{*}{\multicolumn{3}{|c|}{ Male }} \\
\hline & & & & & & & & & \\
\hline & $\mathrm{CE}>\mathrm{EP}$ & $\mathbf{C E}=\mathbf{E P}$ & CE<EP & CE>EP & $\mathrm{CE}=\mathrm{EP}$ & CE<EP & $\mathrm{CE}>\mathrm{EP}$ & $\mathrm{CE}=\mathrm{EP}$ & $\mathbf{C E}<\mathbf{E P}$ \\
\hline L1 & 32 & 0 & 8 & 36 & 0 & 4 & 19 & 0 & 1 \\
\hline L2 & 32 & 0 & 8 & 35 & 0 & 5 & 17 & 0 & 3 \\
\hline L3 & 18 & 0 & 22 & 13 & 0 & 27 & 6 & 0 & 14 \\
\hline L4 & 19 & 0 & 21 & 12 & 0 & 28 & 8 & 0 & 12 \\
\hline L5 & 16 & 7 & 17 & 12 & 5 & 23 & 7 & 2 & 11 \\
\hline L6 & 0 & 7 & 33 & 0 & 6 & 34 & 0 & 4 & 16 \\
\hline L7 & 10 & 0 & 30 & 5 & 0 & 35 & 3 & 0 & 17 \\
\hline L8 & 7 & 0 & 33 & 8 & 0 & 32 & 4 & 0 & 16 \\
\hline L9 & 28 & 0 & 12 & 29 & 0 & 11 & 12 & 0 & 8 \\
\hline L10 & 24 & 0 & 16 & 21 & 0 & 19 & 11 & 4 & 5 \\
\hline L11 & 16 & 6 & 18 & 25 & 3 & 12 & 15 & 2 & 3 \\
\hline L12 & 37 & 3 & 0 & 36 & 4 & 0 & 14 & 4 & 2 \\
\hline \multirow{3}{*}{ Lottery } & \multicolumn{3}{|c|}{ Male } & \multicolumn{3}{|c|}{ male } & \multirow{2}{*}{\multicolumn{3}{|c|}{ female }} \\
\hline & \multicolumn{3}{|c|}{ anger } & \multicolumn{3}{|c|}{ fear } & & & \\
\hline & CE $>E P$ & $\mathbf{C E}=\mathbf{E P}$ & $\mathrm{CE}<\mathrm{EP}$ & CE $>$ EP & $\mathrm{CE}=\mathrm{EP}$ & CE $<$ EP & \multicolumn{3}{|c|}{$\frac{\text { remale }}{\mathrm{CE}>\mathrm{EP} \mathrm{CE}=\mathrm{EP}} \mathrm{CE}<\mathrm{EP}$} \\
\hline L1 & 39 & 0 & 1 & 38 & 0 & 2 & 13 & 0 & 3 \\
\hline L2 & 35 & 0 & 5 & 35 & 0 & 5 & 17 & 1 & 2 \\
\hline L3 & 15 & 0 & 25 & 19 & 0 & 21 & 8 & 0 & 12 \\
\hline L4 & 12 & 0 & 28 & 14 & 0 & 26 & 10 & 1 & 9 \\
\hline L5 & 18 & 5 & 17 & 12 & 7 & 21 & 7 & 3 & 10 \\
\hline L6 & 0 & 6 & 34 & 0 & 5 & 35 & 0 & 4 & 16 \\
\hline L7 & 8 & 0 & 32 & 8 & 0 & 32 & 5 & 0 & 15 \\
\hline L8 & 4 & 0 & 36 & 6 & 0 & 34 & 4 & 0 & 15 \\
\hline L9 & 25 & 0 & 15 & 29 & 0 & 11 & 15 & 2 & 3 \\
\hline L10 & 23 & 0 & 17 & 21 & 0 & 19 & 18 & 0 & 2 \\
\hline L11 & 14 & 13 & 13 & 21 & 9 & 10 & 20 & 0 & 0 \\
\hline L12 & 35 & 5 & 0 & 37 & 3 & 0 & 20 & 0 & 0 \\
\hline
\end{tabular}

Note: $\mathrm{CE}=$ certainty equivalence, $\mathrm{EP}=$ expected payoff. 
We will first compare the certainty equivalence (CE) and expected payoff (EP) of a lottery to investigate the risk patterns among the subjects. It is predicted that people will be; (1) risk-seeking over low probability in gain domain, (2) risk-averse over high probability in gain domain, (3) risk-averse over low probability in loss domain and (4) risk-seeking over high probability in loss domain. This fourfold pattern of risk has been widely observed in the literature, for examples in Tversky and Kahneman (1992), Harbaugh, Krause, and Vesterlund (2010) and Tversky and Wakker (1995). Table 4 shows the number of subjects who are risk seeking (i.e. when $\mathrm{CE}>\mathrm{EP}$ ), risk neutral (i.e. $\mathrm{CE}=\mathrm{EP}$ ) and risk averse (i.e. $\mathrm{CE}<\mathrm{EP}$ ), according to each lottery for emotions fear and anger. The last 3 columns show the risk pattern for both genders without emotion induction (i.e. control groups). The risk patterns shown in the table are consistent with the prediction; more subjects are risk seeking when probability of gain is small or $p=0.05$ (i.e. in L1 and L2) and risk averse when probability of gain is $\mathrm{p} \geq 0.5$ (i.e. L3, L4, L5 and L6) for both genders in fear and anger. The risk patterns are reversed in loss domain, more subjects are risk averse when probability of loss is small $\mathrm{p}=0.05$ (i.e. L7 and L8) and risk seeking when probability of loss is $\mathrm{p}>0.5$ (i.e. L9, L10, L1 1 and L12). How the probability of winning and losing a lottery is evaluated will be explained in the next section.

\subsection{Probability evaluation}

In this subsection, we will examine probability evaluation by both genders when under the influence of emotions fear and anger. What interests us is how males and females, when under the influence of the emotions, evaluate probability (p). We first compare the probability weighing functions for both genders without emotion (control groups), then the weighing functions with emotions compared to control groups.

Figure 1 compares the probability weighing pattern for both genders without influence of emotion. The left panel refers to when choosing lottery in gain domain and right panel refers to loss domain. The diagonal line refers to when $p=w(p)$, or the true probability is equal to the perceived probability. The figure shows females assign larger likelihood

Figure 1: Probability weighing functions for both genders (neutral groups)
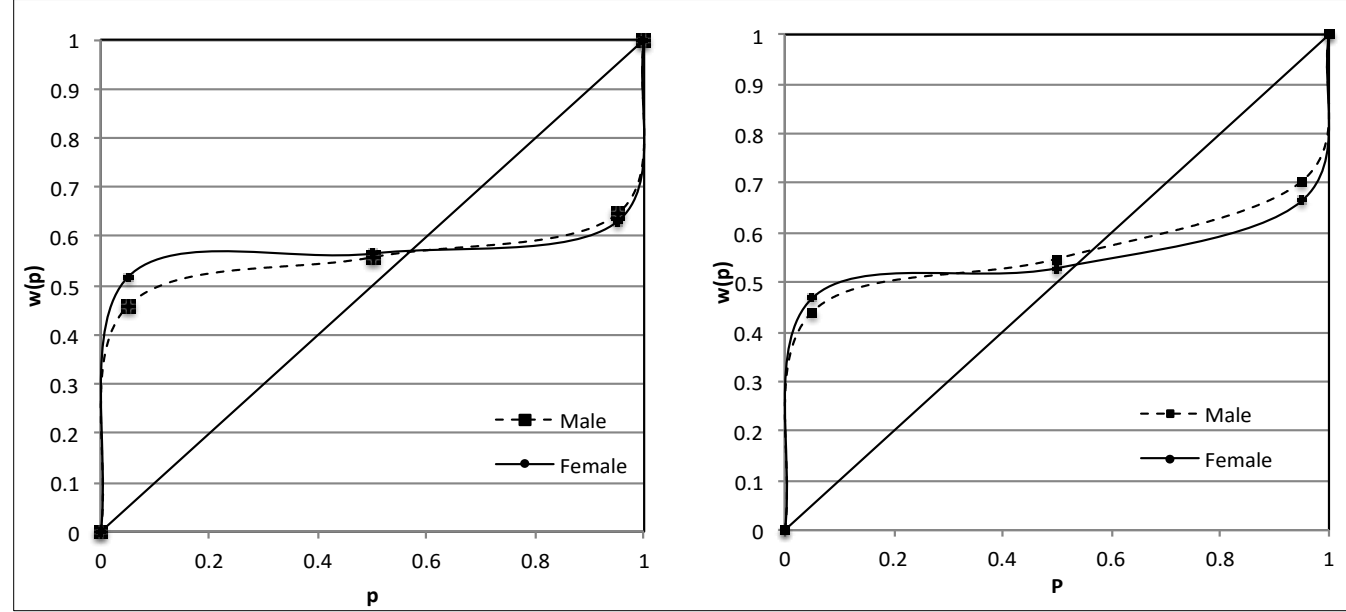
in both winning and losing domains compared to males when probability (p) is 0.05 (i.e. $w(p)>p$ ). But assign lower likelihood of winning and losing when $p=0.95$ (i.e. $w(p)<$ $\mathrm{p})$. Assigning high likelihood of winning when $\mathrm{p}=0.05$ suggests females are too optimistic in gain and too pessimistic in loss domain. Whereas perceiving low likelihood of winning when $\mathrm{p}=0.95$ implies females are pessimistic although the probability of winning is high in gain domain, and overly optimistic by assigning low likelihood of losing in loss domain.

We begin to investigate how emotions could improve the probability weighing of females. We examine effect of; 1) emotion fear in reducing too much overweighing of probability when $\mathrm{p}=0.05$ in gain domain and overly optimistic when $p=0.95$ in loss domain and 2) emotion anger to improve probability weighing when $p=0.95$ in gain domain and 0.05 in loss domain.

Figure 2 makes the comparison. The long dotted line in the figure refers to probability weighing function to the neutral subjects. Based on past findings that anger causes optimistic to risk and fear causes pessimistic to risk, we observe emotion fear reduces over optimistic in evaluating lottery with small probability $(\mathrm{p}=0.05)$ of winning (left panel) but not effective when $\mathrm{p}=0.95$ in loss domain. Subjects are also less pessimistic in a losing lottery with $\mathrm{p}=0.05$ under the influence of emotion anger (right panel).

Figure 2: Comparing probability evaluation under influence of emotions anger and fear for female

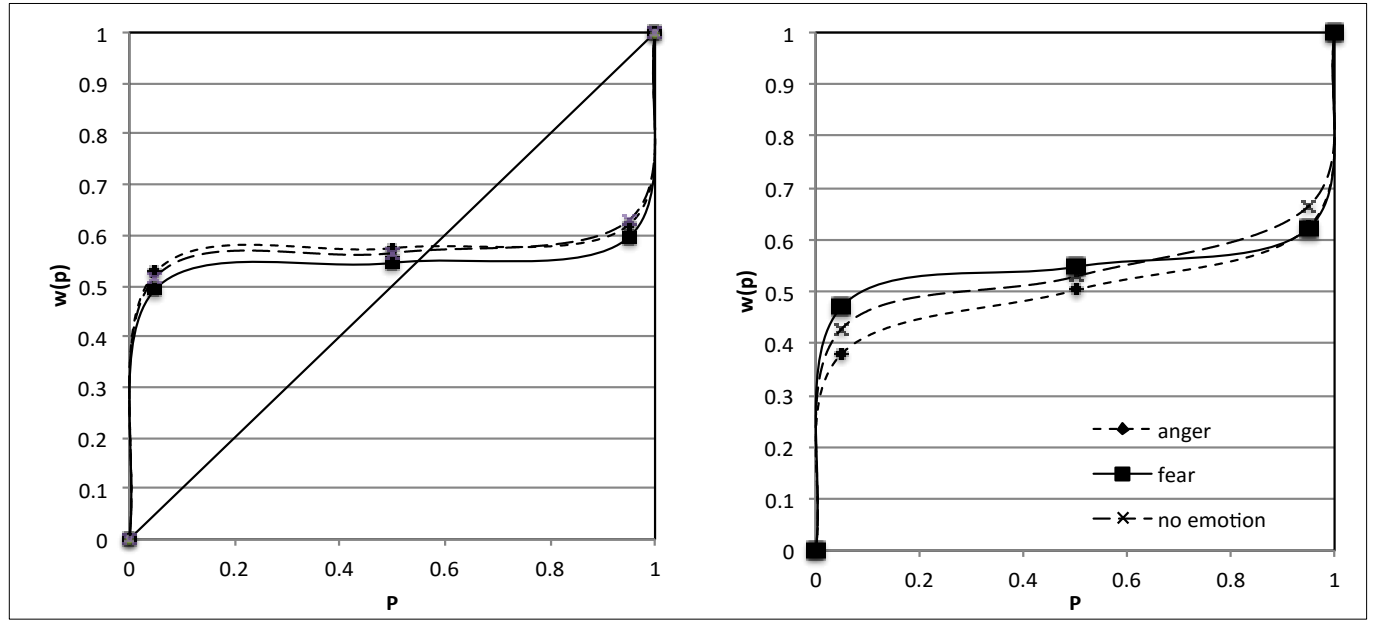

Figure 3 reproduces the evaluation patterns for control groups and groups with emotion for easy comparison. Group with emotion fear assigns lesser likelihood of winning compared to the neutral group when the lottery probability is 0.05 . In the loss domain, females are less pessimistic and assign lower likelihood of losing in the lottery with $\mathrm{p}=0.05$.

The observed probability weighing patterns indicates that sense of uncertainty and uncontrollability induced by emotion fear mitigates over-optimistic in evaluating a lottery with small probability to win. And emotion anger increases optimism when subjects are 
Figure 3: Comparing probability weighing after emotion when $\mathrm{p}=0.05$

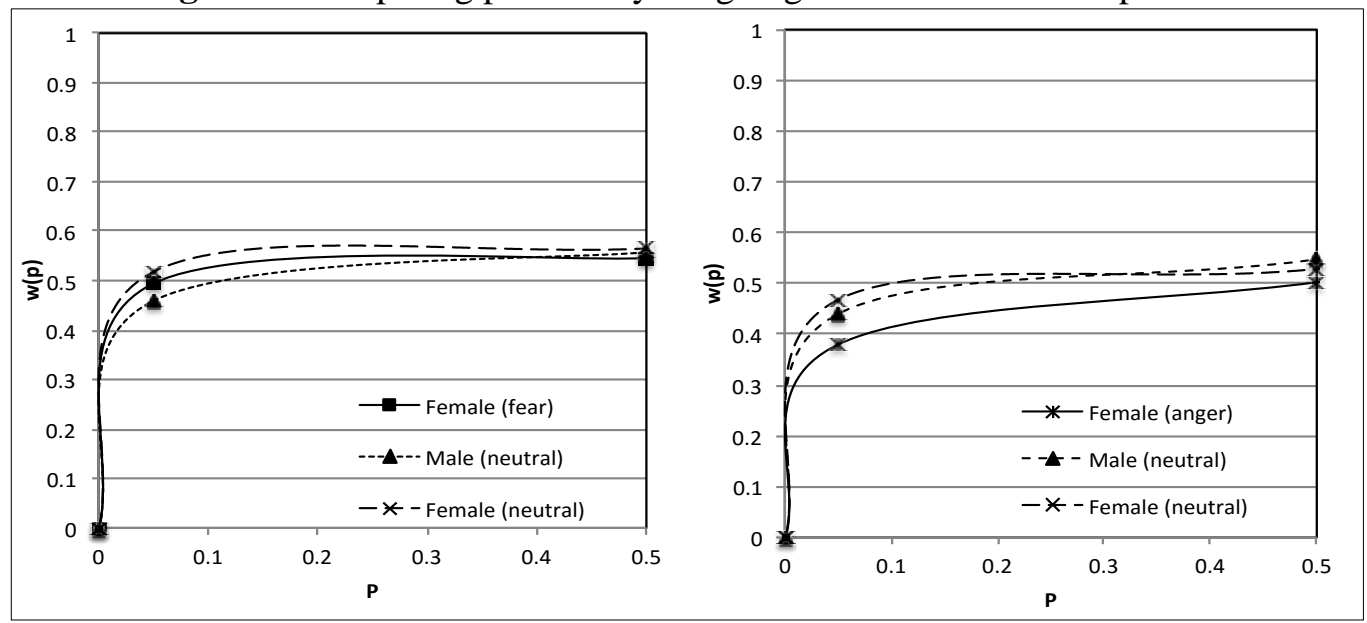

overly pessimistic in evaluating lottery with small probability to lose. The high probability at $p=0.95$ may cause sense of "certainty" to win or lose, which causes emotions to be less effective. The analysis focuses only on females to improve decision making because the same emotions do not affect probability weighing of male subjects (the probability weighing function for male is not reported).

\subsection{Risk behaviors}

The probability weighing patterns observed above do not tell the risk perception of a lottery, especially on how much a lottery is worth to a subject. In this sub-section we examine this question based on the certainty equivalence of the lottery before and after the emotions are induced. Figure 4 (left panel) shows the certainty equivalence of females

Figure 4: Comparing certainty equivalence before and after emotions.

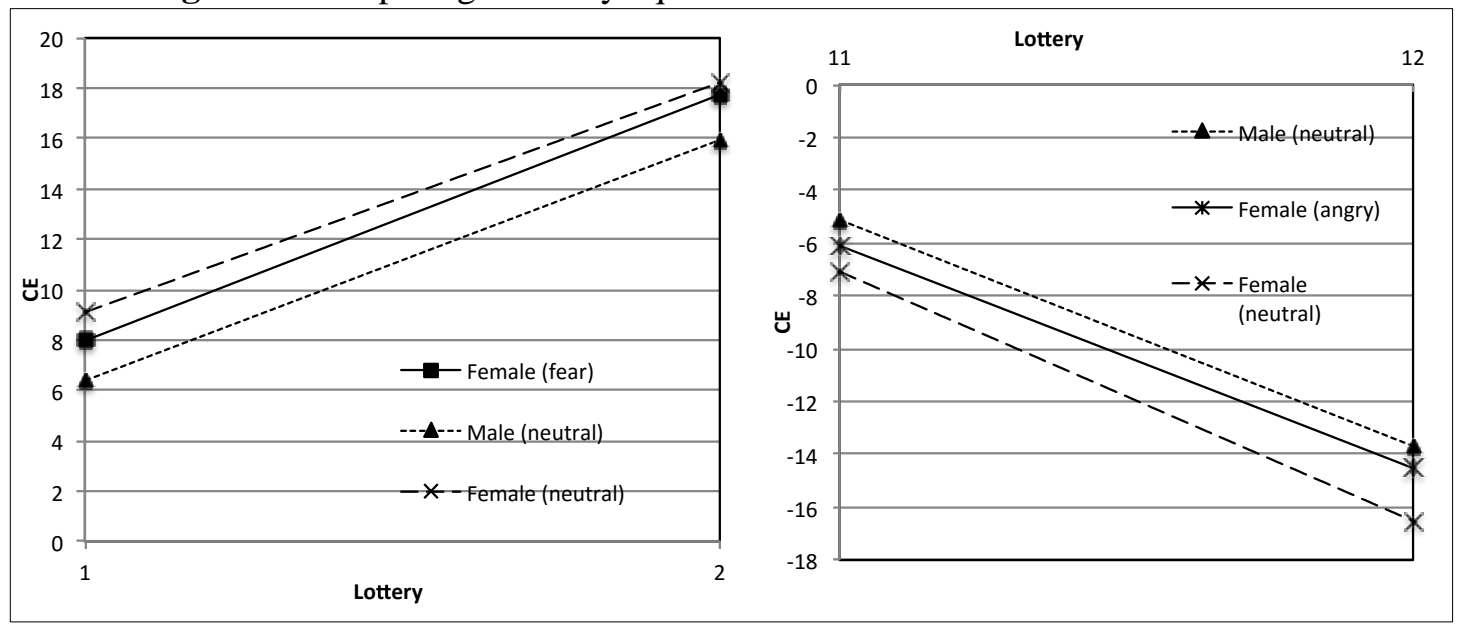


is lower in fear condition and higher when in anger condition (right panel). The emotion fear successfully reduces the tendency to take excessive risk in lottery with low probability to win (i.e. in gain domain), and anger increases optimism in lottery when the probability to lose is very small (i.e. in loss domain).

\section{DISCUSSIONS AND CONCLUSION}

This paper sets out to examine misperception of probability and how it could be mitigated through cognitive appraisal manipulations. Past studies have shown differences in risk tolerance between genders arise from women are more sensitive to probability of a risky prospect. Research by Eriksson and Simpson (2010), Brody (1993) and Lerner et al. (2003) have shown fear of losing among women causes them overreact to risk. With the same level of risk and probability, this body of research has shown women are too pessimistic to risky activities even the probability of losing is small compared to men. This misperception of probability has been one of the contributing factors to the income gap between genders, type of job chosen and tendency to participate in competition. This warrants research to investigate factors that could help to correct the misperception.

Past studies have shown providing more and quality information could improve the decision-making. It has been shown exposing women to more information could reduce fear and help women to interpret the true situation more objectively. However, since emotion fear is associated with psychological dimensions such as sense of lack of control and uncertain over a situation, these dimensions would be carried over even though the emotion fear is reduced (Berkowitz \& Harmon-Jones, 2004). Therefore, identifying and manipulating the psychological dimensions would be more effective. It would also help in the process of designing and conveying the information to the targeted audience. This paper investigates the effects of these two dimensions on probability weighing and risky behaviors. Specifically, we examine can manipulating these two dimensions improve decisions involving risk.

We conducted the analysis in an experimental set up. In a control treatment, we found that women were more sensitive to probability: in both gain and loss domains, women overweigh small probability (i.e. $w(p)>p$ ) and underweigh large probability (i.e. $w(p)<$ p) more than men. This means women put more decision weight on the probability than it should be, and causing women to react to probability more than men. Thus, in gain domain, when the probability of winning is small, women were too optimistic, but in loss domain when the probability of losing is small, women were too pessimistic. On the contrary, when the probability of winning is large, women were more pessimistic than men, and more optimistic when probability of losing is large. Our result conformed to the findings obtained in other studies (Eriksson \& Simpson, 2010; Fehr-Duda et al., 2006).

Oversensitive to emotion fear may have caused women to be more sensitive than men in evaluating probability. As emotion fear is associated with appraisal dimensions "lack of control" and "uncertainty", we explored the effect of another emotion with high in "controllability" and "certainty" dimensions such as emotion anger, to investigate the possibility that the sensitivity to probability under emotion fear could be reduced. Thus, we hypothesized that subjects under the influence of anger overweigh small probability 
of losing less than control group. Subjects under influence of emotion fear should overweigh small probability of winning less than control group. We induced these two emotions using the method in Appraisal Tendency Framework (Lerner \& Keltner, 2000; Smith \& Ellsworth, 1985).

Our findings showed that the two dimensions, lack of control and uncertainty in emotion fear caused subjects, especially women, to overweigh small probability of losing larger than the control group, and high in control and certainty dimensions in emotion anger caused subjects to put more weight on probability of winning than control group. In other words, emotion fear caused subjects to weight probability of losing more than the true probability and emotion anger caused subjects to perceive probability of winning as more highly probable, than control group. This showed that the dimensions indeed have effect on how people evaluate probability. On the effect of mitigating the misperception of probability, we found that emotion fear caused subjects to weigh small probability of winning less than control group. Subjects in emotion anger, overweigh small probability of losing less than control group. These comparisons were made between same gender groups.

However, our results did not find any effect of these two emotions on how male subjects evaluate probability. This may be due to women are more sensitive than men to emotion as observed in Eriksson and Simpson (2010) and Lerner et al. (2003). We also found the subjects in 0.95 treatments did not significantly react to the manipulations in the experiment.

The present paper investigated only two types of emotion, anger and fear. Possible extension is to include other emotions that have similar appraisal dimensions (Smith \& Ellsworth, 1985) such as happiness, pride and contempt, that are high in controllability and certainty dimensions. Emotions with low appraisal in the both dimensions include surprise, hopeful, sadness and shame.

\section{REFERENCES}

Berkowitz, L. (1990). On the formation and regulation of anger and aggression: A cognitive-neoassociationistic analysis. American Psychologist, 45(4), 494 - 503.

Berkowitz, L., \& Harmon-Jones, E. (2004). Toward an understanding of the determinants of anger. Emotion, 4(2), 107 - 130.

Bertrand, M., \& Hallock, K. F. (2001). The gender gap in top corporate jobs. Industrial and Labor Relations Review, 55, 3-21.

Bingley, P., \& Eriksson, T. (2001). Pay spreads and skewness, employee effort and firm productivity.

Brody, L. R. (1993). On understanding gender differences in the expression of emotion. In S. L. Ablon, D. Brown, E. J. Khantzian \& J. E. Mack (Eds.), Human feelings: Explorations in affect development and meaning. NJ: The analytic Press Hillsdale.

Byrnes, J. P., Miller, D. C., \& Schafer, W. D. (1999). Gender differences in risk taking: A meta-analysis. Psychological bulletin, 125(3), 367 - 383.

Camerer, C. F., \& Howard, K. (1989). Decision processes for low probability events:policy implications. Journal of Policy Analysis and Management, 8(4), 565-592. 
DeVaney, E. E., Gorham, S. A., Bechman, J. C., \& Haldeman, V. (1995). Saving and investing for retirement. Journal of the Family Economics and Resource Management Biennial, 1(1), 153-158.

Eckel, C. C., \& Grossman, P. J. (2008). Men, women and risk aversion: Experimental evidence. Handbook of experimental economics results, 1(7), 1061 - 1073.

Eriksson, K., \& Simpson, B. (2010). Emotional reactions to losing explain gender differences in entering a risky lottery. Judgment and Decision Making, 5(3), 159-163.

Fehr-Duda, H., de Gennaro, M., \& Schubert, R. (2006). Gender, financial risk, and probability weights. Theory and decision, 60(2 - 3), 283 - 313.

Felton, J., Gibson, B., \& Sanbonmatsu, D. M. (2003). Preference for risk in investing as a function of trait optimism and gender. Journal of Behavioral Finance, 4(1), 33-40.

Fessler, D. M. T., Pillsworth, E. G., \& Flamson, T. J. (2004). Angry men and disgusted women: An evolutionary approach to the influence of emotions on risk taking. Organizational Behavior and Human Decision Processes, 95(1), 107 - 123.

Finucane, M. L., Alhakami, A., Slovic, P., \& Johnson, S. M. (2000). The affect heutistic in judgements of risks and benefits. Journal of Behavioral Decision Making, 13(1), $1-17$.

Gasper, K., \& Clore, G. L. (1998). The persistent use of negative affect by anxious individuals to estimate risk. Journal of Personality and Social Psychology, 74(5), $1350-1363$.

Harbaugh, W. T., Krause, K., \& Vesterlund, L. (2010). The Fourfold Pattern of Risk Attitudes in Choice and Pricing Tasks. The Economic Journal, 120(545), 595 - 611.

Harris, C. R., Jenkins, M., \& Glaser, D. (2006). Gender differences in risk assessment: Why do women take fewer risks than men. Judgment and Decision Making, 1(1), 48-63.

Holtgrave, D. R., \& Weber, E. U. (1993). Dimensions of risk perception for financial and health risks. Risk Analysis, 13(5), 553 - 558.

Kahneman, D., \& Tversky, A. (1979). Prospect theory: an analysis of decision under risk. Econometrica, 47(2), 263-292.

Kugler, T., Connolly, T., \& Ordonez, L. D. (2010). Emotion, decision and risk: betting on gambles versus betting on people. Journal of Behavioral Decision Making, 25(2), 123-134.

Lerner, J. S., \& Keltner, D. (2000). Beyond valence: Toward a model of emotion-specific influences on judgement and choice. Cognition \& Emotion, 14(4), 473-493.

Lerner, J. S., \& Keltner, D. (2001). Fear, anger and risk. Journal of Personality and Social Psychology, 81(1), $146-159$.

Lerner, J. S., \& Tiedens, L. Z. (2006). Portrait of the angry decision maker: How appraisal tendencies shape anger's influence on cognition. Journal of Behavioral Decision Making, 19(2), 115 - 137.

Lerner, J. S., Gonzalez, R. M., Deborah A, S., \& Baruch, F. (2003). Effects of fear and anger on perceived risks of terrorism: A national field experiment. Psychological Science, 14(2), 144 - 150.

Levy, A. G., \& Baron, J. (2005). How bad is a $10 \%$ chance of losing a toe? Judgments of probabilistic conditions by doctors and laypeople. Memory \& cognition, 33(8), 1399 - 1406.

Loewenstein, G. (2000). Emotions in economic theory and economic behavior. American Economic Review, 90(2), 426-432. 
Loewenstein, G. F., Weber, E. U., Hsee, C. K., \& Welch, N. (2011). Risk as feelings. Psychological bulletin, 127(2), 267.

Niederle, M., \& Vesterlund, L. (2007). Do women shy away from competition? Do men compete too much? The Quarterly Journal of Economics, 122(3), 1067 - 1101.

Olsen, R. A., \& Cox, C. M. (2001). The influence of gender on the perception and response to investment risk: the case of professional investors. Journal of Psychology and Financial Markets, 2(1), 29 - 36.

Rachel, C., \& Gneezy, U. (2009). Gender differences in preferences. Journal of Economic Literature, 47(2), 1 - 27.

Slovic, P., Fischhoff, B., \& Lichtenstein, S. (2000). Facts and fears: Understanding perceived risk. The perception of risk. Sterling, VA: Earthscan.

Smith, C. A., \& Ellsworth, P. C. (1985). Patterns of cognitive appraisal in emotion. Journal of Personality and Social Psychology, 48(4), 813-838.

Sunden, A. E., \& Surette, B. J. (1998). Gender differences in the allocation of assets in retirement saving plans. American Economic Review, 88(2), 207 - 211.

Tversky, A., \& Kahneman, D. (1992). Advances in prospect theory: Cumulative representation of uncertainty. Journal of Risk and Uncertainty, 5(4), 297-323.

Tversky, A., \& Wakker, P. (1995). Risk attitudes and decision weights. Econometrica, 63(6), 1255-1280.

Watson, J., \& Mc Naughton, M. (2007). Gender differences in risk aversion and expected retirment benefits. Financial Analysts Journal, 63(4), 53 - 63.

Watson, J., \& Robinson, S. (2003). Adjusting for tisk in comparing the performance of male and female controlled SMEs. Journal of Business Venturing, 18(6), 773 - 788.

Weber, E. U., Blais, A.-R., \& Betz, N. E. (2002). A domain-specific risk-attitude scale: Measuring risk perceptions and risk behaviors. Journal of Behavioral Decision Making, 15(4), 263 - 290. 